\title{
ACERCA DE MARTA FONCERRADA DE MOLINA
} (1928-1988)

\author{
Martha Ilia NáJera C. \\ Centro de Estudios Mayas, \\ IIF, UNAM
}

Con el fallecimiento de Marta Foncerrada de Molina desaparece una de las historiadoras del arte que más aportaciones ha brindado al conocimiento de las obras mayas prehispánicas.

Reconocida ampliamente entre especialistas, fue elegida como representante de la Universidad Nacional Autónoma de México, ante la Union Académique Internationale, con la finalidad de volver a publicar el Corpus Antiquitatum Americanensium. En uno de los que serían sus últimos viajes, se traslada a Barcelona, España y con gran éxito logra que en la LXI Asamblea General se apruebe el proyecto de la publicación de esta trascendental obra. El número IX de la colección queda a su cargo en colaboración con Amalia Cardós de Méndez. Después de una acuciosa selección, analizan algunas figurillas de Jaina que se encuentran en el Museo Nacional de Antropología; pero la maestra Foncerrada no alcanzó a ver publicada esta bella edición, pues cuatro meses antes, el 25 de mayo de 1988 , muere la distinguida investigadora.

La maestra nació el 3 de enero de 1928 en la Ciudad de México. Realizó sus primeros estudios en la Escuela Fitz Gibbon e ingresó más tarde a la Universidad Iberoamericana, a la carrera de Historia de las Artes Plásticas, cuya maestría alcanza en 1963, con mención honorífica. Desde que elige el tema de su tesis muestra una franca inclinación por el arte maya, pues estudia la ornamentación de la arquitectura Puuc. Esta investigación fue dirigida por el eminente arqueólogo Alberto Ruz, y a partir de entonces nació una cordial afinidad entre sus temas de estudio respectivos. 
En 1964 ingresa a la Facultad de Filosofía y Letras de la UNAM para estudiar el doctorado en Historia.

Durante 23 años fue miembro del cuerpo de investigadores del Instituto de Investigaciones Estéticas, y elaboró varios libros y un sinnúmero de artículos. En su primera obra La escultura arquitectónica de Uxmal, publicada en 1965, interpreta de manera novedosa, pero siempre dentro de estrictos lineamientos científicos, el estilo arquitectónico de Uxmal y define los rasgos esenciales del estilo Puuc. Es éste un estudio iconográfico que sirve de punto de partida para otros de diversa índole y que además incluye aportaciones para la historia y comprensión de los grupos mayas.

También colabora en diversas revistas e importantes obras, nacionales y extranjeras, con un gran número de artículos en los que realiza análisis e interpretaciones profundos, en especial de la pintura en vasijas mayas de los diversos estilos arquitectónicos mayas.

Es a partir del descubrimiento de los frescos de Cacaxtla en 1975, cuando surge en Marta Foncerrada un nuevo interés científico; entusiasmada ante la presencia de la cultura maya en un lugar tan lejano de su hábitat original, como es Tlaxcala, inicia un estudio sistemático de las pinturas, logrando asimismo interpretaciones originales que quedaron plasmadas en diversos artículos publicados a partir de 1976 y que constituirían la base de una tesis doctoral que su deceso le impidió concluir.

Es indispensable mencionar su actividad docente, a la que consagró gran parte de su vida, despertando gran número de vocaciones, que continuó, a través de los años, conduciendo y consolidando con laboriosa y fatigante dedicación.

Así, desde que terminó sus estudios, impartió diversos cursos en la Escuela de Historia del Arte de la Unniversidad Iberoamericana, entre los que se cuentan el de "Arte Moderno", "Metodología". Más tarde en 1964 forma parte del cuerpo docente de nuestra casa de estudios en la Escuela de Cursos Temporales y en 1968 ingresa en la Facultad de Filosofía y Letras haciéndose cargo por veinte años de diversos cursos sobre Historia del Arte, en especial del periodo prehispánico, tanto en la licenciatura como en posgrado.

Por su buen juicio y conocimientos, es elegida en diversas ocasiones como Miembro del Consejo Técnico de la Escuela 
de Historia del Arte en la Universidad Iberoamericana y luego como Consejera; más adelante es nombrada Miembro de la Comisión Dictaminadora del Instituto de Investigaciones Filológicas, por nuestro Centro de Estudios Mayas de la UNAM, responsabilidad en la que siempre se desempeñó con objetividad y entrega.

Otra de sus facetas constituye la labor de difusión, pues dio a conocer a personas no especializadas, el significado y la relevancia del arte prehispánico, a través de cursillos, visitas guiadas, conferencias y escribiendo artículos, de esta manera, contribuyó a que nuestra comunidad se interesara y comprendiera al mundo prehispánico, se sintiera heredera de esta tradición y cooperara a salvaguardar nuestro patrimonio cultural.

$\mathrm{El}$ amor que Marta Foncerrada de Molina prodigó a su trabajo queda plasmado en toda su labor, que servirá como guía y ejemplo para otros investigadores.

Hay maestros que no se olvidan; su recuerdo permanece al lado de su obra.

\section{PUBLICACIONES}

1965 La Escultura Arquitectónica de Uxmal, Universidad Nacional Autónoma de México, Instituto de Investigaciones Estéticas, México (Estudios y fuentes del Arte en México, núm. 21), 207 pp.

1968 Uxmal. La Ciudad del Dios de la Lluvia, Fondo de Cultura Económica, México (Presencia de México, 5).

1976 y Sonia Lombardo de Ruiz, Vasijas pintadas mayas en contexto arqueológico: catálogo, Universidad Nacional Autónoma de México, Instituto de Investigaciones Estéticas, 1979 (Estudios y fuentes del Arte en México, 39), $364 \mathrm{pp}$.

1988 Las figurillas de Jaina, Campeche en el Museo Nacional de Antropología, textos Marta Foncerrada de Molina y Amalia Cardós de Méndez, Universidad Nacional Autónoma de México, Instituto de Investigaciones Estéticas/Instituto Nacional de Antropología e Historia, México (Corpus antiquitatum americanensium), $133 \mathrm{pp}$. 


\section{Artículos}

1958 "La alegría de pintar", México en la Cultura, periódico Novedades, septiembre 6, México.

1961 "El estilo Puuc", México en la Cultura, periódico Novedades, noviembre 12, México.

1962 "Pedro Coronel, un arte monumental", revista Siempre, junio 6, México.

1963 "Situación cronológica del estilo Puuc", Actas y Memorias del XXV Congreso Internacional de Americanistas, vol. I, México.

1964 "Fechas de radiocarbono en el área maya", Estudios de Cultura Maya, vol. IV, Universidad Nacional Autónoma de México, Facultad de Filosofía y Letras, Seminario de Cultura Maya, México, pp. 141-166.

1965 "La catedral gótica símbolo del dualismo en la Edad Media", México en la Cultura, periódico Novedades, febrero, México.

1965 "Ideas básicas sobre las artes plásticas y su función en el México actual", México en la Cultura, periódico Novedades, octubre 19, México.

1967 "El dios maya de la lluvia en el Códice de Dresde y en los huesos esgrafiados de la tumba del Templo I de Tikal", Anales del Instituto de Investigaciones Estéticas, vol 9, núm. 36, Universidad Nacional Autónoma de México, Instituto de Investigaciones Estéticas, México, pp. 15-24.

1968 "Lo olmeca y lo maya en sus orígenes", Museo Nacional de Antropología, Sección de Difusión Cultural, México (Los olmecas, 9).

1968 "El vaso maya de Yalloch", Anales del Instituto de Investigaciones Estéticas, vol. 10, núm. 37, Universidad Nacional Autónoma de México, Instituto de Investigaciones Estéticas, México, pp. 23-36.

1970 "Reflexiones sobre la decoración de un vaso maya", Anales del Instituto de Investigaciones Estéticas, vol. 10, núm. 39, Universidad Nacional Autónoma de México, Instituto de Investigaciones Estéticas, México, pp. 79-86.

1970 "Uxmal, Zayil, Kabah y Labná", Caminos de México, núms. 48-49, Goodrich Euzkadi, México.

1970 "Estilos arquitectónicos en Mesoamérica", Museo Nacional de Antropología, Sección de Difusión Cultural, México (Arquitectura en Mesoamérica, 1). 
1970 Reseña bibliográfica a Cien obras maestras del Museo Nacional de Antropología, de Ignacio Bernal, Anales del Instituto de Investigaciones Estéticas, vol. X, núm. 39, Universidad Nacional Autónoma de México, Instituto de Investigaciones Estéticas, México.

1971 Reseña bibliográfica a la obra Cuarenta siglos de plástica mexicana. Arte Prehispánico, Anales del Instituto de Investigaciones Estéticas, vol. X, núm. 40, Universidad Nacional Autónoma de México, Instituto de Investigaciones Estéticas, México.

1972 "La pintura rupestre", El arte olmeca, coordinación Beatriz de la Fuente, Artes de México, núm. 154, año XIX, Comercial Vadrosa, México, pp. 63-69.

1972 "Pintura y expresión en los vasos mayas" Revista de la Universidad de México, Universidad Nacional Au:6noma de México, vol. XXVIII, núm. 4, diciembre 1972, México.

1972 "Maya vase painting of the Classic period: an evaluation of the formal characteristic of polychrome decoration .." Simposia on the Art of the Latin American, Tulane University, New Orleans, pp. 1-28.

1972 "El pensamiento mítico maya en un vaso del Clásico Tardío", Religión en Mesoamérica, vol. XII, Mesa Redonda de la Sociedad Mexicana de Antropología, México.

1972 "Las reseñas críticas de Francisco de la Maza", Anales del Instituto de Investigaciones Estéticas, vol. XI, núm. 41, Universidad Nacional Autónoma de México, Instituto de Investigaciones Estéticas, México.

1973 "Teoría y método en la obra de Justino Fernández. Sobre arte prehispánico", Anales del Instituto de Investigaciones Estéticas, vol. XII, núm. 42, Universidad Nacional Autónoma de México, Instituto de Investigaciones Estéticas, México, pp. 49-55.

1973 Resención al libro Copan Home of The Mayan Gods, de Francis Robicsek, publicado por The Museum, of the American Indian Heye Foundatione, New York, 1972, en Anales del Instituto de Investigaciones Estéticas, vol. XII, núm. 42, Universidad Nacional Autónoma de México, Instituto de Investigaciones Estéticas, México.

1974 "Origen del arte maya y el desarrollo del mascarón como forma integrada a la arquitectura", La escultura 
clásica maya, coordinación de Paul Gendrop, Artes de México, núm. 167, año XX, Comercial Vadrosa, México.

1974 "La pintura prehispánica en cerámica", Historia de la Pintura Mexicana, Cía. Impresora y Litográfica Juventud, S. A., México.

1974 "El ritual Maya en un vaso del Museo Reitberg de Zurich", Anales del Instituto de Investigaciones Estéticas, vol. XII, núm. 43, Universidad Nacional Autónoma de México, Instituto de Investigaciones Estéticas, México, pp. 37-48.

1974 "Reflexiones en torno a Palenque como Necrópolis", Primera Mesa Redonda de Palenque, Palenque, Chiapas, A Conference on the Art Iconography and Dynastic History of Palenque, Part II, Merle Green Robertson Editor, The Robert Louis Stevenson School, Pre-Columbian Art Research Project, Pebble Beach, California, pp. 77-79.

1975 "Temas y motivos de la pintura de cerámica maya", XIII Mesa Redonda de la Sociedad Mexicana de Antropología, Arqueología, 2, México, pp. 91-101.

1976 "El Sacrificio por Decapitación en Palenque", Segunda Mesa Redonda de Palenque, Palenque, Chiapas, The Art, Iconography and Dynastic History of Palenque, Part. III, Merle Green Robertson Editor, Pre-Columbian Art Research Project, Pebble Beach, California, pp. $177-180$.

1976 "El enano en la plástica maya", Anales del Instituto de Investigaciones Estéticas, vol. XIII, núm. 45, Universidad Nacional Autónoma de México, Instituto de Investigaciones Estéticas, México, pp. 45-57.

1976 "In memoriam. Eric Thompson", Anales del Instituto de Investigaciones Estéticas, vol. XIII, núm. 45, Universidad Nacional Autónoma de México, Instituto de Investigaciones Estéticas, México.

1977 "El comerciante en la cerámica pintada del clásico tardío maya (600-900 d.C.)", Del arte: Homenaje al doctor Justino Fernández, Universidad Nacional Autónoma de México, Instituto de Investigaciones Estéticas, México, pp. 45-52.

1977 "Maya Vase Painting of the Classic Period: an Evolution of the Form Characteristics of Polycrome Designs Based on a Selection of a Limited Number of Archae- 
ological Maya Vases", Revista Mexicana de Estudios Antropológicos, Sociedad Mexicana de Antropología, t. XXIII, 2, México, pp. 247-270.

1977 "La pintura mural de Cacaxtla, Tlaxcala", Anales del Instituto de Investigaciones Estéticas, vol. XII, núm. 46, Universidad Nacional Autónoma de México, Instituto de Investigaciones Estéticas, México, pp. 5-20.

1978 "Reflexiones en torno a la pintura mural de Cacaxtla", Comunicaciones, 15, 2do. Simposio Proyecto Puebla, Tlaxcala, Fundación Alemana para la Investigación Científica, México, pp. 103-130.

1978 "The Cacaxtla Mural: An Example of Cultural Contact", Ibero-Amerikanisches Archiv, Neve Falge Jahrgangy Heftz, Berlin.

1979 "La secularización del hombre en la pintura de vasijas mayas", La dicotomía entre arte culto y arte popular, 1er. Coloquio Internacional de Historia del Arte del Instituto de Investigaciones Estéticas, 1975, Zacatecas, Universidad Nacional Autónoma de México, Instituto de Investigaciones Estéticas, México (Estudios de arte y estética, 14).

1980 "La pintura mural de Cacaxtla", Methodological approaches to Precolumbian Art, Actes Du XLII Congres International Des Americanistes, vol. VII, Paris.

1980 "Mural painting in Cacaxtla and Teotihuacan Cosmopolitism", Tercera Mesa Redonda de Palenque, Part. 2, The Palenque Round Table Series, Volume V, University of Texas Press, Austin, pp. 183-189.

1982 "Rasgos fundamentales de la pintura prehispánica", Historia del arte mexicano, Editorial Salvat, vol. 3, cap. 1, Secretaría de Educación Pública/Instituto Nacional de Bellas Artes, México.

1982 "La pintura mural de Cacaxtla", Historia del arte mexicano, Editorial Salvat, vol. 3, Secretaría de Educación Pública/Instituto Nacional de Bellas Artes, México.

1982 "Signos glíficos relacionados con Tláloc en murales de la batalla en Cacaxtla", Anales del Instituto de Investigaciones Estéticas, vol. XIII, núm. 50, Universidad Nacional Autónoma de México, Instituto de Investigaciones Estéticas, México, pp. 23-34.

1983 "Los murales de Cacaxtla: muerte en la guerra", Jahr- 


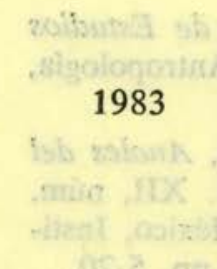

buch für Geschichte Lateinamerikas, vol. IV, Alemania Federal, Colonia.

"El atavío del guerrero en la época mexica", El arte efimero en el mundo hispánico, 4 ? Coloquio Internacional de Historia del Arte del Instituto de Investigaciones Estéticas, Morelia, 1978, Universidad Nacional Autónoma de México, Instituto de Investigaciones Estéticas, México (Estudios de arte y estética, 17).

1983 "La exaltación del gobernante maya", Anales del Instituto de Investigaciones Estéticas, vol. 14, núm. 53, Universidad Nacional Autónoma de México, Instituto de Investigaciones Estéticas, México, pp. 7-15.

1983 Reseña bibliográfica a Kohunlich. Una ciudad maya del clásico temprano, varios autores, Anales del Instituto de Investigaciones Estéticas, vol. 14, núm. 53, Universidad Nacional Autónoma de México, Instituto de Investigaciones Estéticas, México.

1984 Reseña bibliográfica a Art of Aztec Mexico. Treasures Tenochtitlan, de H. B. Nicholson y Eloise Quiñones, Anales del Instituto de Investigaciones Estéticas, vol. 53, Universidad Nacional Autónoma de México, Instituto de Investigaciones Estéticas, México.

1986 "Semblanza académica de Paul Westheim", Artes Plásticas, Universidad Nacional Autónoma de México, Escuela de Artes Plásticas, México.

1986 "La representación de pájaros en el arte teotihuacano", Anales del Instituto de Investigaciones Eséticas, vol. XV, núm. 57, Universidad Nacional Autónoma de México, Instituto de Investigaciones Estéticas, México.

1986 "Donald Robertson 1919-1984", Anales del Instituto de Investigaciones Estéticas, vol. XIV, núm. 55, Universidad Nacional Autónoma de México, Instituto de Investigaciones Estéticas, México.

1986 Reseña bibliográfica a Studies in Ancient American and Europan Art, de Thomas F. Reese, Anales del Instituto de Investigaciones Estéticas, vol. XIV, núm. 56, Universidad Nacional Autónoma de México, Instituto de Investigaciones Estéticas, México.

1987 "Cacaxtla: muerte en la guerra", Arte funerario, Cololoquio Internacional de Historia del Arte del Instituto de Investigaciones Estéticas, 2 vols. Universidad Nacional Autónoma de México, Instituto de Investigaciones 
Estéticas, México. (Cuadernos de historia del arte, 41).

1987 "Un fragmento de pintura mural en Cacaxtla, Palenque y el Popol Vuh", Anales del Instituto de Investigaciones Estéticas, vol. XV, núm. 58, Universidad Nacional Autónoma de México, Instituto de Investigaciones Estéticas, México, pp. 29-33.

1988 "Arte maya. Interacción artística y regional (300-1200 d.C.), Proyección extraterritorial", Simpatías y diferencias. Relaciones del Arte Mexicano con el de América Latina, X Coloquio Internacional del Instituto de Investigaciones Estéticas, México, D. F., 1985, Universidad Nacional Autónoma de México, Instituto de Investigaciones Estéticas, México (Estudios de arte y estética, 28), pp. 35-44. 